\title{
Features of the formation of taste sensations
}

\author{
Vladimir Litvyak ${ }^{1}$, Alexey Sysa ${ }^{2}$, \\ Anatoly Batyan², Vyacheslav Kravchenko²
}

\author{
1 - Scientific and Practical Centre for Foodstuffs of the National Academy of Sciences of \\ Belarus, Minsk, Belarus \\ 2 - Belarusian State University, International Sakharov Environmental Institute, \\ Minsk, Belarus
}

\section{Keywords:}

Taste

Chemoreception

Carbohydrate

Protein

Fractal

Complementarity

\section{Article history:}

Received

21.01.2019

Received in revised

form 26.03.2019

Accepted

30.09.2019

\section{Corresponding author:}

Vladimir Litvyak

E-mail:

besserk1974@

mail.ru

DOI:

10.24263/2304-

974X-2019-8-3-15

\section{Abstract}

Introduction. An important characteristic that reflects the quality and forms the price of any food product is its organoleptic properties, for example, taste sensations arising from the use of the product. Currently, there is not enough data that reliably describes the mechanism of occurrence of taste sensations.

Materials and Methods. The subject of research was carbohydrates, proteins, and sodium chloride. The phase structure was studied by $\mathrm{X}$-ray diffraction. Diffraction curves were recorded on an HZG 4A X-ray diffractometer (Carl Zeiss, Jena) using radiation of copper $(\mathrm{CuK} \alpha)$ filtered by nickel. Scanning electron micrographs of native starch granules were obtained using a LEO 1420 scanning (scanning) electron microscope.

Results and discussion. The phase and morphological structure of carbohydrates (monosaccharides, disaccharides and polysaccharides) and sodium chloride were studied, as well as the morphological structure of milk proteins. Among carbohydrates, glucose, fructose, sucrose, maltose, lactose, and rhamnose have been found to have a crystalline structure, native starches have an amorphous-crystalline (transitional or intermediate) structure, and maltodextrins have an amorphous structure. Salt has a crystalline structure.

It is shown that in the formation of taste sensations, the geometry of the taste buds of the tongue and the geometry of the analyzed taste objects, which are created in accordance with the principle of complementarity (for example, a lock), are of great importance. Taste language analyzers and analyzed taste objects are universal in size and have a fractal structure. The smallest indivisible fractal unit is an electron. The fractal structure of the taste analyzers is continuous, and the analyzed taste objects are intermittent and depend on the degree of purity of the object. Many substances (protein molecules, etc.) have a complex hierarchical structure and are able to gradually demonstrate their taste characteristics, that is, at each of the hierarchical levels of organization, these substances have their own taste characteristics. Moreover, it often happens that at the last hierarchical level, the geometry of these substances tends to a spherical (neutral) shape. Smell as well as taste is one of the types of chemoreception, therefore, the features of the formation of sensations of smell are similar to the formation of taste sensations.

Conclusion. A hypothesis has been put forward about chemoreception, in particular about the formation of taste sensations, which made it possible to lay the foundations of a mathematical description of taste. 


\section{Food Technology}

\section{Introduction}

An important characteristic reflecting the quality and forming the price of any food product are organoleptic properties, for example, arising from the use of the product taste.

Despite the large number of scientific works [1-13] devoted to the study, until now there is no universally recognized and reliable mechanism for the occurrence of taste sensations. Thus, the features of the formation of a bitter taste are discussed in scientific works $[1-4,6,7]$, sour - [8-10], and taste by the minds - [12]. The effect of ethyl alcohol and narcotic substances on the perception of bitter taste is shown in the study [1]. The taste perception of amino acids is described in a scientific paper [13]. It is believed that the perception of taste in a certain way depends on the anatomy of taste analyzers $[14,15]$.

The aim of this research is to study the distinguishing features of the formation of taste sensations in humans.

\section{Materials and methods}

\section{Materials}

The object of research were carbohydrates (glucose, fructose, sucrose, maltose, lactose, rhamnose, native starch (potato, corn, rice, pea) and maltodextrins (potato, corn)), and also proteins (dry milk products (whey protein concentrate KSB-UV-80 (JSC Schuchinsky MSZ)), whole milk powder for baby food with a fat content of $25 \%$ (Bellact), skimmed milk powder (Bellact) cheese demineralized whey 50\% (Institute of Meat and Dairy Industry), whey protein concentrate with microparticles Promilk $630 \mathrm{M}$, whey protein concentrate Simplesse 100E)) and sodium chloride $(\mathrm{NaCl})$.

\section{Radiography method}

Analysis. The phase structure was investigated by radiography [16, 17]. Samples for recording X-ray diffractograms were prepared in the form of monolithic flat-cylindrical Tablets with a smooth surface. Press pressure was not less than $100 \mathrm{~kg} / \mathrm{cm}^{2}$. The duration of exposure to the press - from 15 to 30 minutes, depending on the type of sample. All Tablets were the same size. Diffraction curves were recorded on an X-ray diffractometer HZG 4A (Carl Zeiss, Jena) using copper $\left(\mathrm{CuK}_{\alpha}\right)$ radiation filtered by nickel. All curves were obtained in absolutely identical conditions, in step mode of discrete scanning.

Crystallinity calculation. Radiographs of the samples were described in the «reflection» mode. The degree of crystallinity was calculated as the ratio of intensities of $I_{\mathrm{K}} / I_{\mathrm{o}}$, where $I_{\mathrm{K}}$ is the intensity of X-ray diffraction on crystal regions; $I_{0}$ is the total intensity of X-ray diffraction.

\section{Scanning Electron Microscopy (SEM)}

Sample preparation. Metallization of native starch preparations was carried out with gold in the EMITECH K 550X vacuum unit.

Analysis. Scanning electron micrographs of native starch granules were obtained using a LEO 1420 scanning (raster) electron microscope (Germany) [18, 19]. 


\section{Results and discussion}

\section{Classical atomic and physiological ideas about the formation of taste sensations}

Taste is one of the types of chemoreception. This is a feeling that arise when exposed to a variety of substances on the taste receptors located on the taste buds of the tongue, as well as the back wall of the pharynx, soft palate, tonsils, epiglottis. The scheme of the location of taste receptors on the human tongue is shown in Figure 1 [14, 15, 20, 21]. The sense of taste develops with the direct participation of the branches of the facial and glandular nerves, providing taste sensitivity to the front $2 / 3$ and back $1 / 3$ of the tongue, respectively.

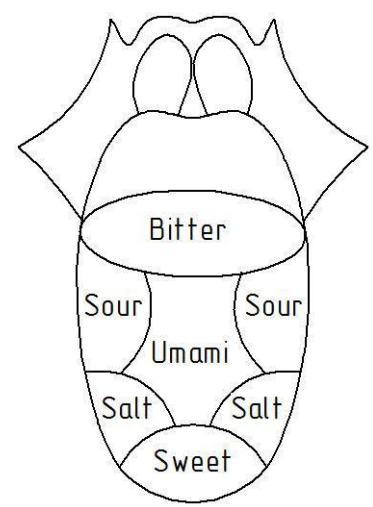

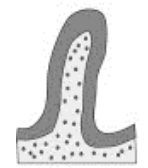

Filiform

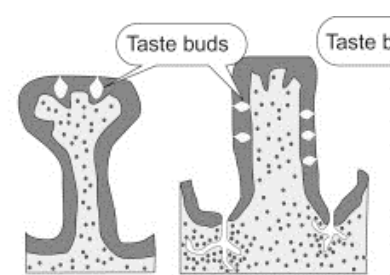

Foliate

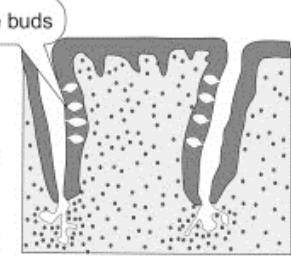

Circumvallate

Figure 1. Scheme of the location of taste buds on the human tongue

Briefly, there are four main flavors: sweet, bitter, sour and salty. However, there are also other types of taste: astringent, pungent, minty, alkaline, metal, etc. and many flavors.

Information from the taste receptors is transmitted by afferent fibers of the facial, lingual and vagal cranial nerves to the nucleus of a single pathway of the medulla oblongata, then switching occurs in the nuclei of the thalamus and then in the postcentral gyrus and islet (lat. insula) of the cerebral cortex, where the taste sensations are formed [14]. According to others, the cortical end of the taste system is parahippocampal or hook gyrus (lat. gyrus parahippocampalis or gyrus uncinatus) and in the hippocampus (lat. hippocampus) [15].

According to modern concepts, all substances consist of atoms, molecules and ions united by means of various types of chemical bonds (covalent, ionic, hydrogen) and other interactions. So, the atom (gr. ö $\tau$ o $\mu$ o $\varsigma$ - indivisible, uncut) - a particle of matter of microscopic size and mass, the smallest part of the chemical element, which is the carrier of its properties. The molecule - the smallest particle of matter that determines its properties and is capable of independent existence, which is a set of two or more atoms. The ion (Greek. ióv-running) - electrically charged non-elementary particle (atom, molecule, free radical), having a positive or negative charge of electricity, is divisible by the electron charge (positively charged ion - cation, negatively charged ion - anion) [22, 23].

All the variety of chemical (inorganic and organic) molecules has its own unique spatial geometry. Organic compounds are carbon compounds formed primarily by hybrid orbitals. Hybridization of orbitals is a hypothetical process of mixing different (s, p, d, f) orbitals of the central atom of a polyatomic molecule with the appearance of identical orbitals, equivalent in their characteristics [22]. The main expected equilibrium configurations of organic molecules are presented in Table 1. 
Expected equilibrium configurations of organic molecules

Table 1

\begin{tabular}{|c|c|}
\hline Hybrid orbitals & Equilibrium configuration \\
\hline $\mathrm{sp}$ & Linear \\
\hline $\mathrm{sd}$ & Angular \\
\hline $\mathrm{sp}^{2}$ & Flat equilateral triangle \\
\hline $\mathrm{sp}^{3}$ & Tetrahedron \\
\hline $\mathrm{sp}^{2} \mathrm{~d}$ & Square \\
\hline $\mathrm{sp}^{3} \mathrm{~d}^{2}$ & Octahedron \\
\hline $\mathrm{sp}^{3} \mathrm{~d}$ & Trigonal bipyramide \\
\hline $\mathrm{sp}^{3} \mathrm{~d}^{4}$ & Dodecahedron \\
\hline
\end{tabular}

\section{Experimental and theoretical research results}

\section{Carbohydrate research} $2-4$.

The results of our X-ray structural analysis of organic compounds are shown in Figure

Thus, data in Figure 2 shows the radiographs of carbohydrates: glucose, fructose, rhamnose, mannose, lactose and maltose, Figure 3 - radiographs of sucrose, and Figure 4 radiographs of carbohydrates: native starch (potato, corn, rice, pea) and maltodextrins (potato and corn).

Normal, grown in a pure solution of the crystal (i.e., a substance with a molecular structure which is natural for it a grate) sucrose is a complex multi-faceted (more than 15 faces) form of sphenoidale-semiprismal class (a combination of six crystallographic forms) and belongs to wedge-like rhombic or monoclinically systems with the three crystallographic axes in space: vertical (C), horizontal (B) and the axis (A) inclined at angles $103^{\circ} 30^{\prime}$ to the vertical, and $90^{\circ}$ to the horizontal (Figure 2 and Table 2) $[24,25]$. The ratio of the lengths of the axes within the crystal $\mathrm{A}: \mathrm{B}: \mathrm{C}=1,2595: 1,0: 0,8782.15$ types of sucrose crystals are known, double crystals are often observed, the shape of the crystals depends on the conditions of the crystallization process, impurities in the initial solution and the degree of supersaturation of sucrose with this solution (Table 2).

Main characteristics of sucrose crystals

Table 2

\begin{tabular}{|l|c|c|c|c|c|c|}
\hline \multicolumn{1}{|c|}{ Indicators } & Meas. unit & \multicolumn{5}{c|}{ Values } \\
\hline Mass of the crystal & $\mathrm{mg}$ & 0,1 & 0,5 & 20 & 200 & 2000 \\
\hline Length of the crystal & $\mathrm{cm}$ & 0,057 & 0,097 & 0,33 & 0,71 & 1,54 \\
\hline Volume of the crystal & $\mathrm{cm}^{3}$ & 0,000063 & 0,00032 & 0,013 & 0,126 & 1,264 \\
\hline Crystal surface & $\mathrm{cm}^{2}$ & 0,0099 & 0,029 & 0,339 & 1,573 & 7,302 \\
\hline Number of crystals in 1 g & $\mathrm{ps}$. & 10000 & 2000 & 50 & 5 & 0,5 \\
\hline Surface of all the crystals & $\mathrm{sm}^{2}$ & 99,1 & 58,0 & 17,0 & 7,9 & 3,7 \\
\hline
\end{tabular}



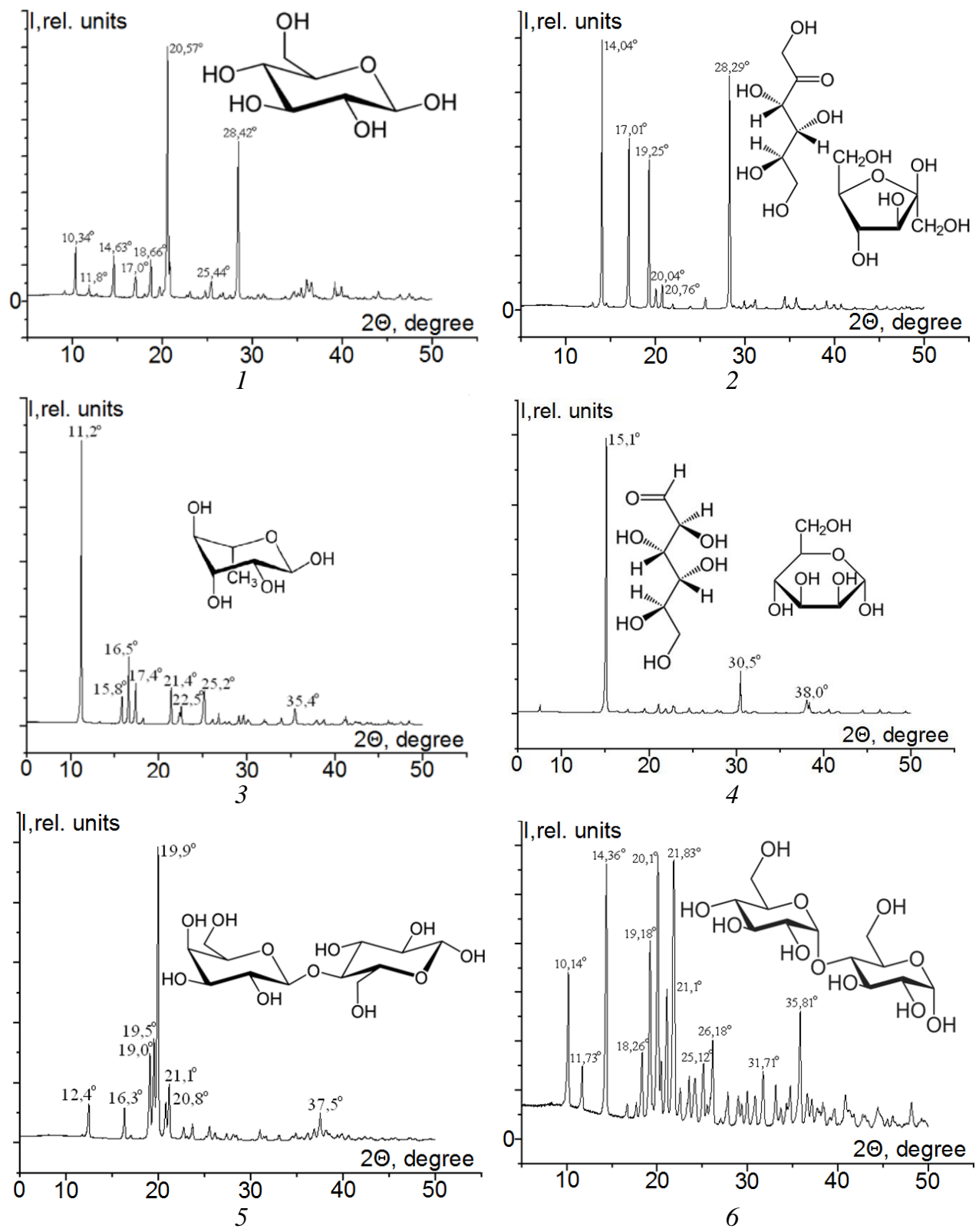

Figure 2 - Radiographs of carbohydrates

1 - glucose; 2 - fructose; 3 - rhamnose; 4 - mannose; 5 - lactose; 6 - maltose 

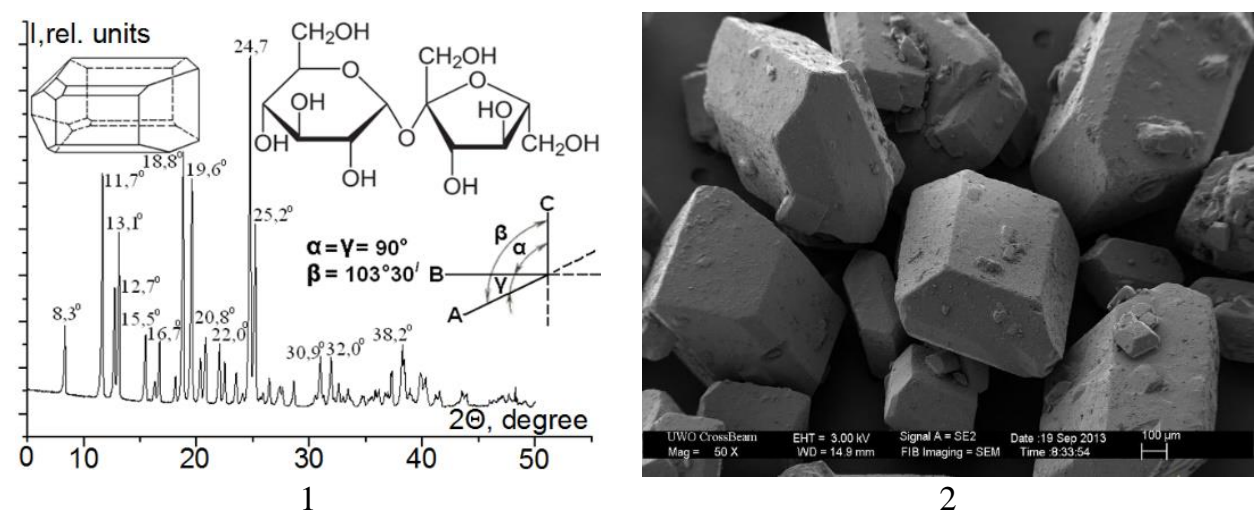

Figure 3. Sucrose:

1 - radiograph; 2 - scanning electron microphotography.

Features of the amorphous crystal structure of the starch granules are shown in Figure 5. Starch granules consist of alternating between crystalline and amorphous regions [26]. The amorphous part of the granules forms a continuous phase and includes crystalline starch formation such as lamellae. Depending on the structural organization of the crystal areas of starch granules are divided into $A$ - and $B$-type. $A$-type refers to the starch of cereals, b-type starch tubers and bulbs. The crystal structures of $A$ - and $B$-types belong to the amylosis part of the starch and consist of parallel twisted right double helices packed antiparallel. Each spiral contains six residues of $\alpha$-D-glucopyranose. Within the spiral formed channel with a diameter of $0,5 \mathrm{~nm}$. The conformations of the double helix of amylose in $A$ - and $B$-structures are the same, but the $A$-structure is characterized by an orthorhombic unit cell with parameters $a=1,190 \mathrm{~nm}, b=1,770 \mathrm{~nm}, c=1,052 \mathrm{~nm}$, while the B structure is characterized by a hexagonal unit cell with parameters $a=b=1,85 \mathrm{~nm}, c=1,04 \mathrm{~nm}$. Complexes of amylose with lipids in the natural starch form a structure of $V$-type. The degree of crystallinity of natural starch depends on its origin and is $15-45 \%$.

Figures 2 and 3 show that there are compounds with a crystalline structure (glucose, fructose, sucrose, maltose, lactose and rhamnose) among carbohydrates, with an amorphouscrystalline (transition or intermediate) structure (native starches) and with an amorphous structure (maltodextrins). It should be noted that carbohydrates with a crystal structure have a pronounced sweetness, and carbohydrates with an amorphous-crystalline and amorphous structure did not have a well-pronounced sweet taste. It should be noted that the geometry of the crystals in each of the studied compounds having a crystal structure is unique.

Substances having an amorphous-crystalline or amorphous (especially amorphous) structure in an ideal state form a supramolecular structure that tends in its form to be spherical (Figure 6). Ball - a geometric body; the set of all points of space, located from the center at a distance, no more than a given. This distance is called the radius of the ball. The ball is formed by rotating a circle or semicircle around its fixed diameter. This diameter is called the axis of the ball, and both ends of the specified diameter - the poles of the ball. The surface of the ball is called a sphere: a closed ball includes this sphere, an open ball excludes. All flat sections of the ball are circles. The largest circle lies in the section passing through the center of the ball (sphere), and is called the big circle. Its radius is equal to the radius of the ball (sphere). Thus, the ball (sphere) - an infinite number of ordered arranged circles. 

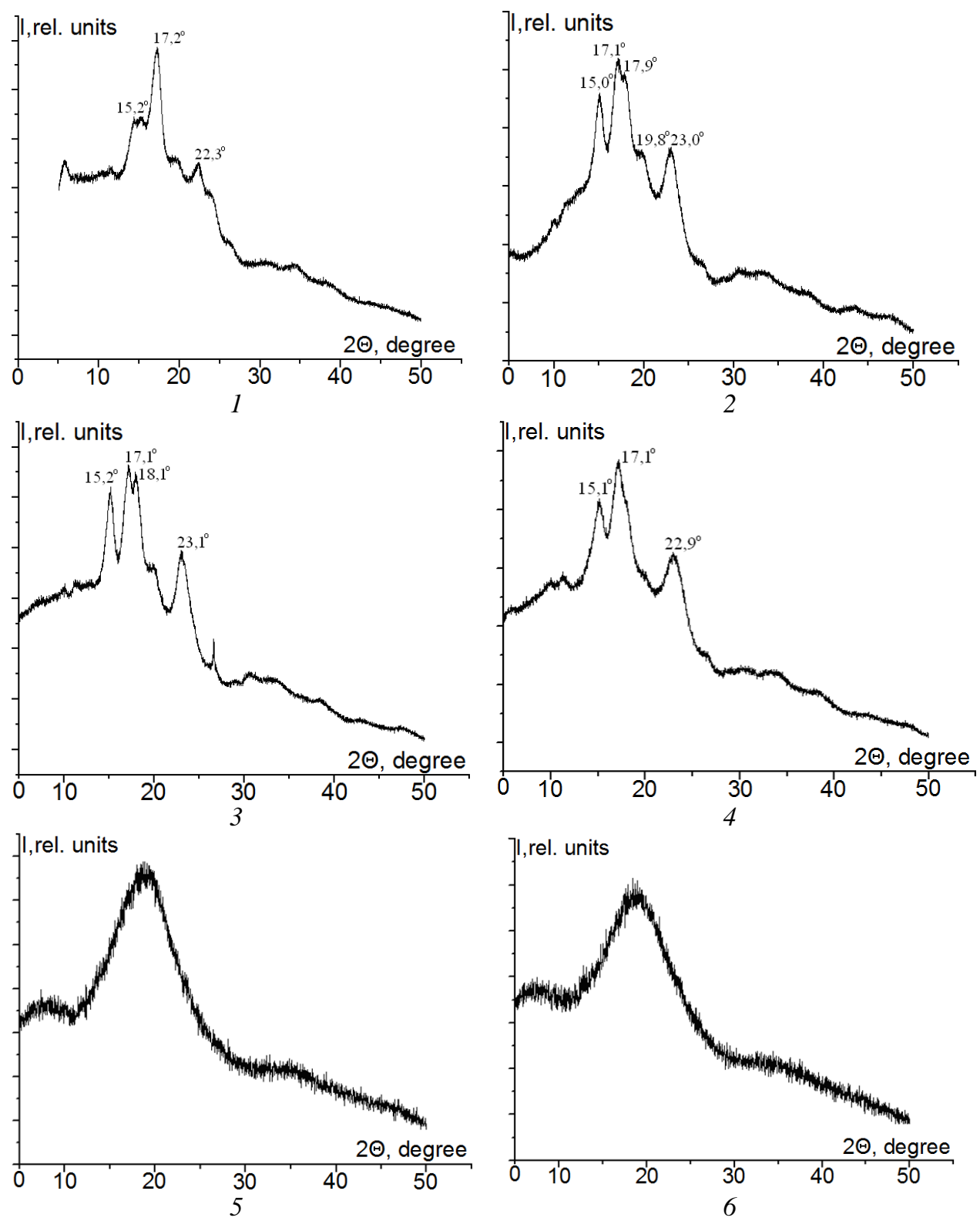

Figure 4. Radiographs of carbohydrates:

Native starch: 1 - potato; 2 - corn; 3 - rice; 4 - pea.

Maltodextrins: 5 - potato; 6 - corn. 
Amylose helix

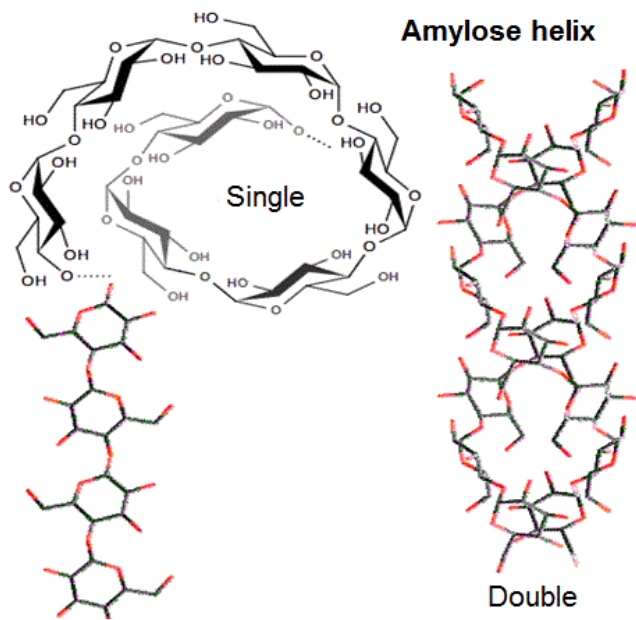

Double

a

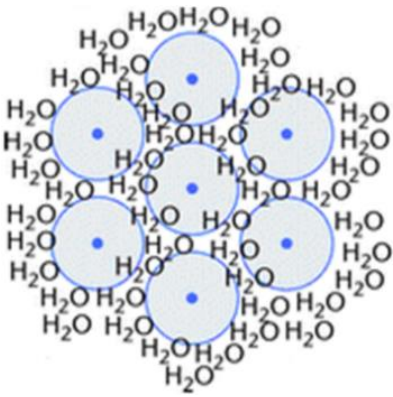

Type A

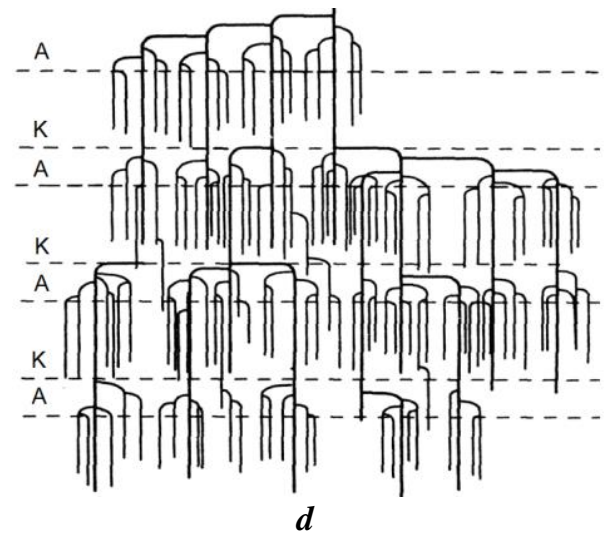

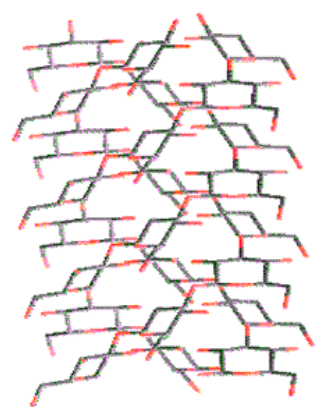

Triple

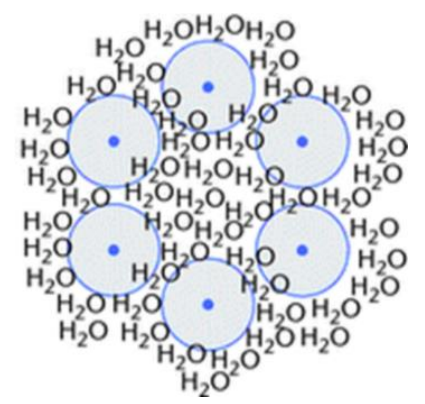

Type B

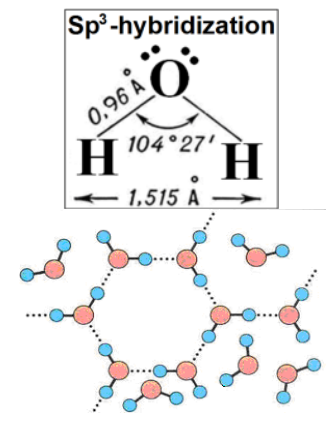

c

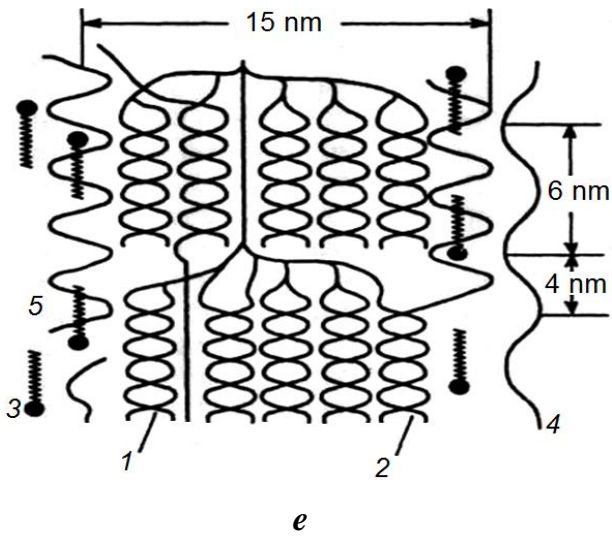

Figure 5. Features of amorphous crystal structure of native starch:

$a$ - possible variants for twisting amylose; $b$ - crystalline areas of starch (crystallites); $c$ - the structure of the water molecule; $d$ - the structure of amylopectin:

$A$ - amorphous lamella, $K$ - crystal lamella;

$e$ - the structure of the starch granules:

1 - amylopectin spirals; 2 - hybrid spirals of amylose and amylopectin; 3 - free lipids; 4 - free amylose; 5 - $V$-structure of amylose 


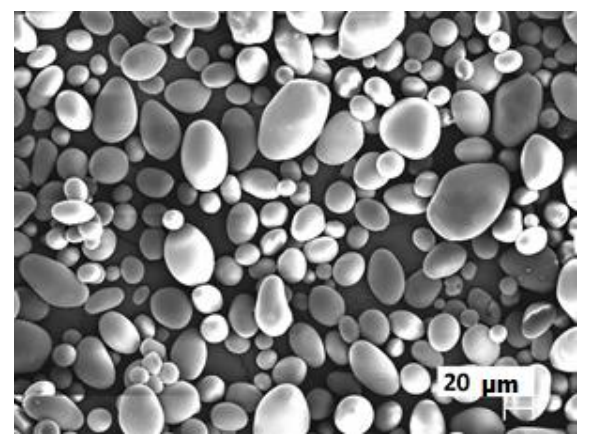

1

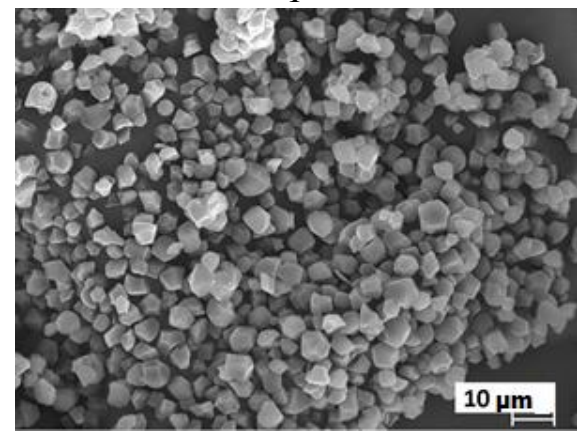

3

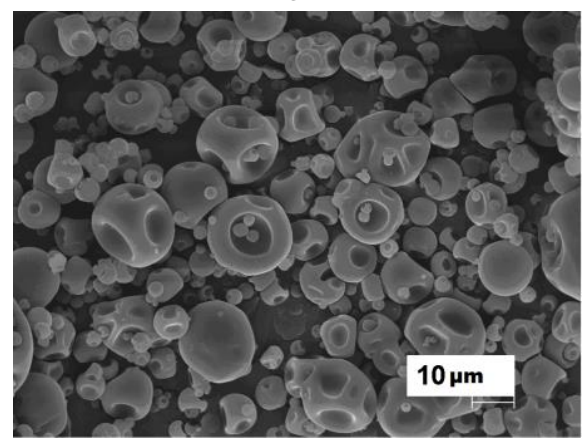

5

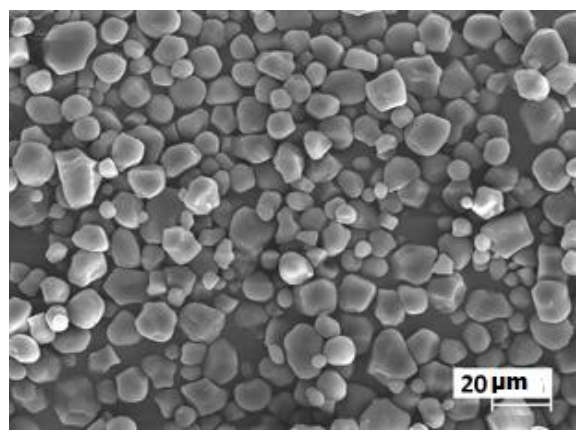

2

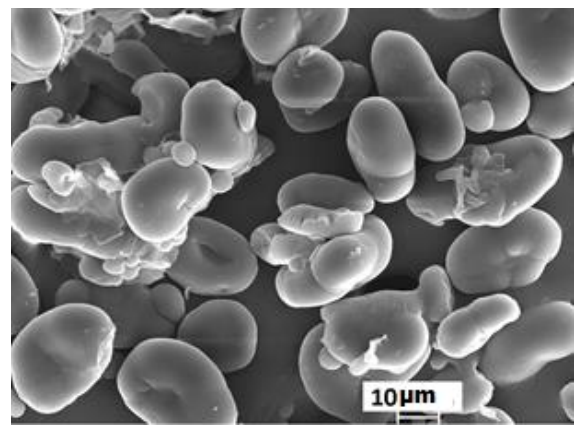

4

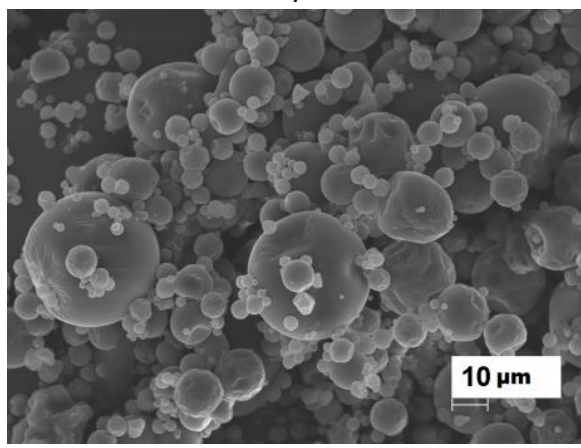

6

Figure 6 - Morphological analysis of carbohydrates.

Native starch: 1 - potato; 2 - corn; 3 - rice; 4 - pea; Maltodextrins: 5 - potato; 6 - corn

A circle is a special (unique) geometric Figure that combines two opposites: finiteness and infinity. Infinity in the circle can be considered the length of the circle (it has no beginning or end), and the limb - the diameter and chords of the circle (they are always limited to two points lying on the circle).

Thus, the matter striving to get out of the state of infinity (non-manifestation) and become finite (manifested) chose the circle for its primary organization, since it is an intermediate stable state between infinity and finiteness. The circle can be otherwise called finite infinity or infinite finiteness, i.e. it is a figure in which two dialectical opposites converged. In this case, the number PI $-\pi$ (the ratio of the circumference and its diameter) $[27,28]$ can be considered as an asymmetry between infinity and finiteness. In addition, the length of an infinitely large circle can be considered as an infinite straight line, because in 
these conditions, the curvature is infinitely small, it can be equated to zero. Therefore, the circle, the diameter of which tends to infinity can be taken as a straight line, which closes itself. At the same time, if the diameter of the circle tends to zero, the length of the circle can be considered a straight line equal to the point.

\section{Salt research}

Sodium chloride ( $\mathrm{NaCl}$, sodium chloride) is a sodium salt of hydrochloric acid, known in everyday life as Table salt $[29,30]$. It occurs in sea water in the form of the mineral halite (rock salt). Pure sodium chloride is a colorless crystals, but with various impurities its color can acquire blue, purple, pink, yellow or gray. Sodium chloride has a face-centered cubic crystal structure, with the ions $\mathrm{Na}^{+}$and $\mathrm{Cl}^{-}$have octahedral coordination geometry (Figure 7).
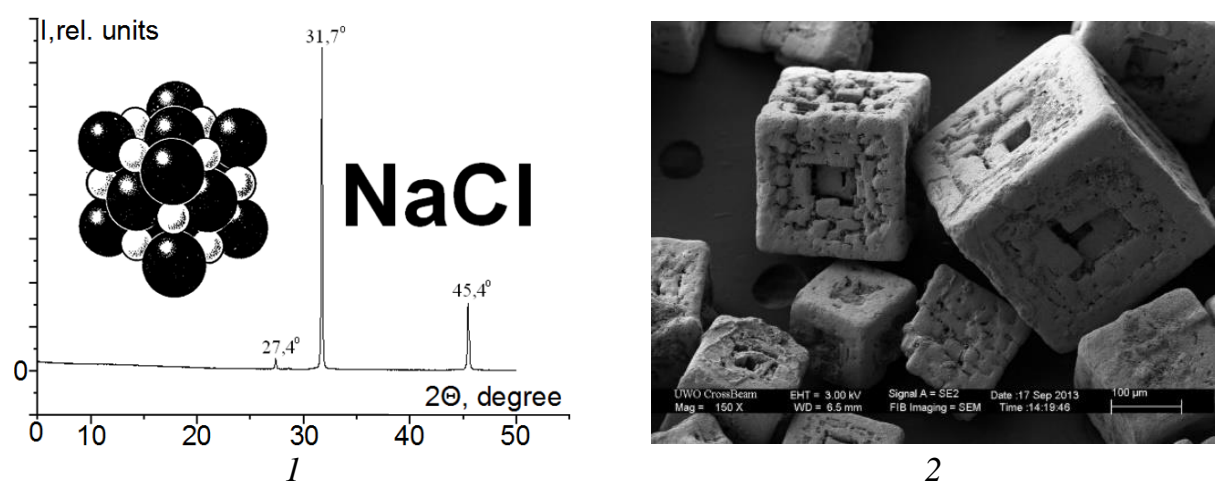

Figure 7 - Features of the structure of sodium chloride:

1 - radiograph; 2 - scanning electron microphotography

\section{Proposed hypothesis of chemoreception on the example of the formation of taste sensations}

It is known that the number of regular and semi-regular polyhedra in nature is limited $[31,32]$. Thus, Table 3 shows all known regular polyhedra, and Table 4 shows all semiregular polyhedra.

Natural crystals have only some elements of symmetry, among which are: the center of symmetry, symmetry axes of the second order, the third order, the fourth order, the sixth order, the mirror-rotating axes of the fourth and third order, the plane of symmetry [31]. The axis of symmetry of the fifth order in the crystals does not occur, since the angle of the Pentagon is $108^{\circ}$, and this number is not divided by the angle of $360^{\circ}$. There are 32 combinations of symmetry elements peculiar to crystals. These combinations are called symmetry types or classes of crystals.

Thirty-two types (classes) of symmetry crystals are divided into six systems or crystal symmetry [33]:

1. A cubic system (sometimes called isometric) with third-and fourth-order symmetry axes (fourth-order axes can be of mirror-rotating type).

2. Tetragonal system with one fourth-order axis.

3. Hexagonal or trigonal system (includes rhombohedral crystals) with one axis of the sixth order or one axis of the third order. 
4. Rhombic system with two or three planes of symmetry or axes of symmetry of the second order, forming right angles to each other.

5. Monoclinic system with one plane or one axis of the second order, or with both elements of symmetry.

6. Triclinic system with the center of symmetry or without symmetry elements.

Main characteristic of regular solids (Platonic solids)

Table 3

\begin{tabular}{|c|c|c|}
\hline Name & Appearance & Characteristic \\
\hline 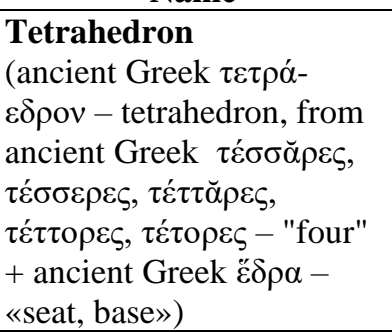 & & $\begin{array}{l}\text { face }- \text { triangle, } \\
\text { faces }-4 \text {, } \\
\text { ribs }-6 \text {, } \\
\text { vertices }-4 \text {, } \\
\text { faces at the top }-3 \text {, } \\
\text { symmetry group }- \\
\text { tetrahedral (Th). }\end{array}$ \\
\hline 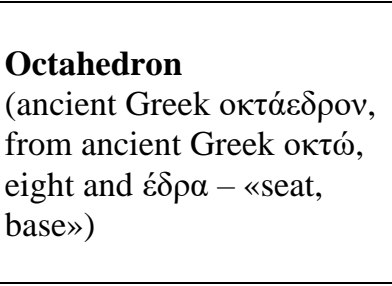 & & $\begin{array}{l}\text { face }- \text { triangle, } \\
\text { faces }-8, \\
\text { ribs }-12, \\
\text { vertices }-6, \\
\text { faces at the top }-4, \\
\text { symmetry group - } \\
\text { octahedral (Oh). }\end{array}$ \\
\hline 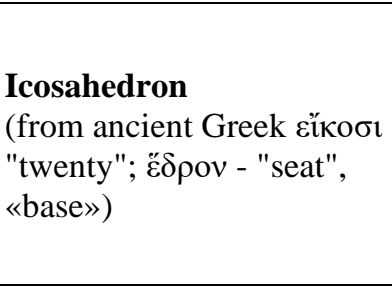 & & $\begin{array}{l}\text { face }- \text { triangle, } \\
\text { faces }-20, \\
\text { ribs }-30, \\
\text { peaks }-12, \\
\text { faces at the top }-5 \text {, } \\
\text { symmetry group - } \\
\text { icosahedral (Ih). }\end{array}$ \\
\hline 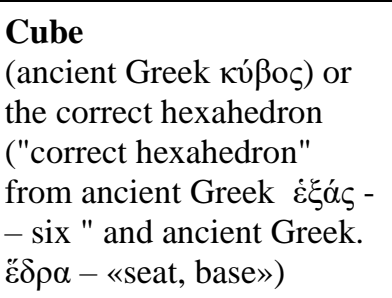 & & $\begin{array}{l}\text { face }- \text { square, } \\
\text { faces }-6, \\
\text { ribs }-12, \\
\text { vertices }-8, \\
\text { faces at the top }-3 \text {, } \\
\text { symmetry group - } \\
\text { octahedral (Oh). }\end{array}$ \\
\hline $\begin{array}{l}\text { Dodecahedron } \\
\text { (from Greek } \delta \omega ́ \delta \varepsilon \kappa \alpha- \\
\text { twelve and Greek } \varepsilon \delta \rho \circ \nu- \\
\text { «seat, base») }\end{array}$ & & $\begin{array}{l}\text { face - Pentagon, } \\
\text { faces }-12, \\
\text { ribs }-30 \text {, } \\
\text { vertices }-20 \text {, } \\
\text { faces at the top }-3 \text {, } \\
\text { symmetry group - } \\
\text { icosahedral (Ih). }\end{array}$ \\
\hline
\end{tabular}


Table 4

Main characteristic of semi-regular polyhedra (Archimedean and Catalan solids)

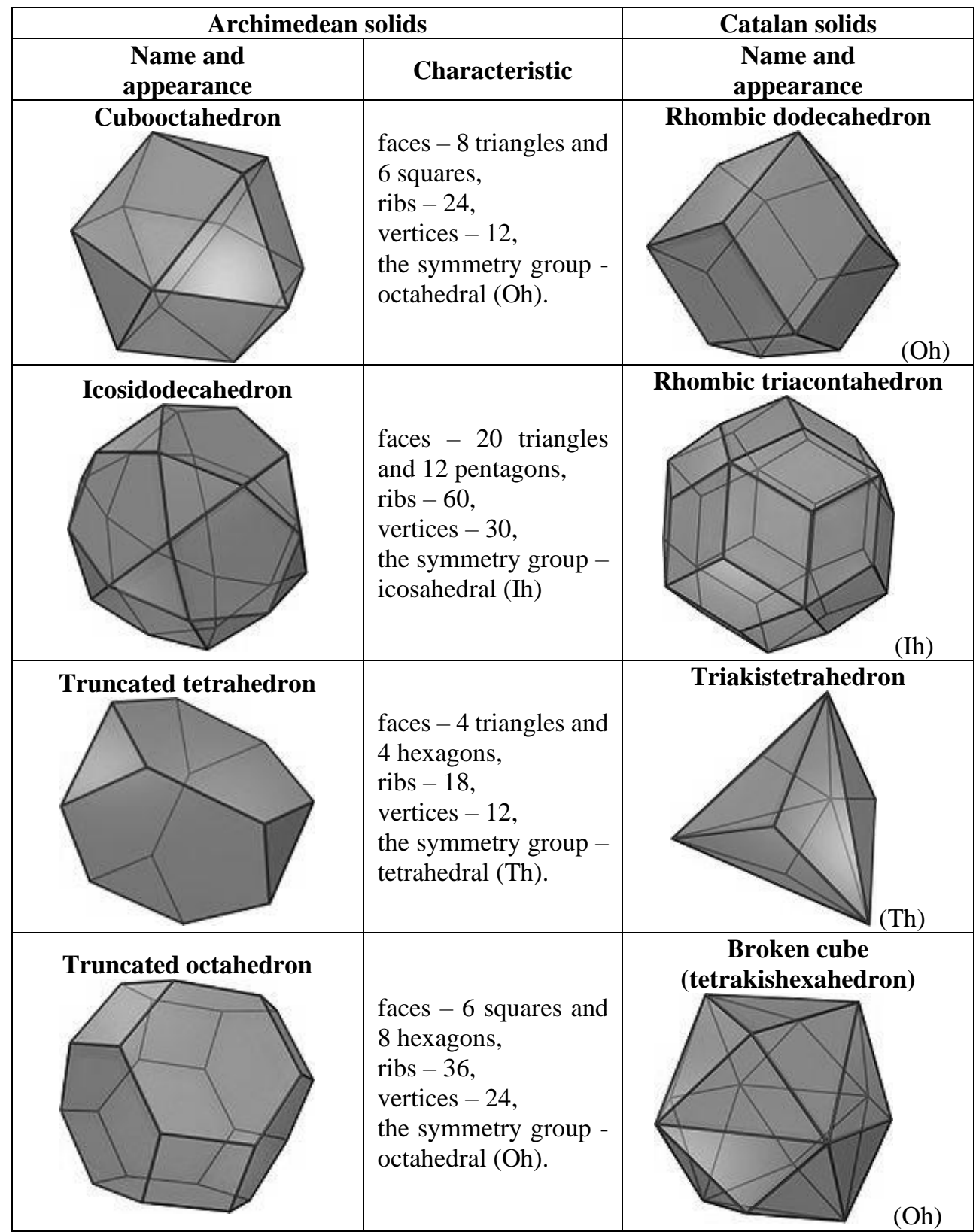




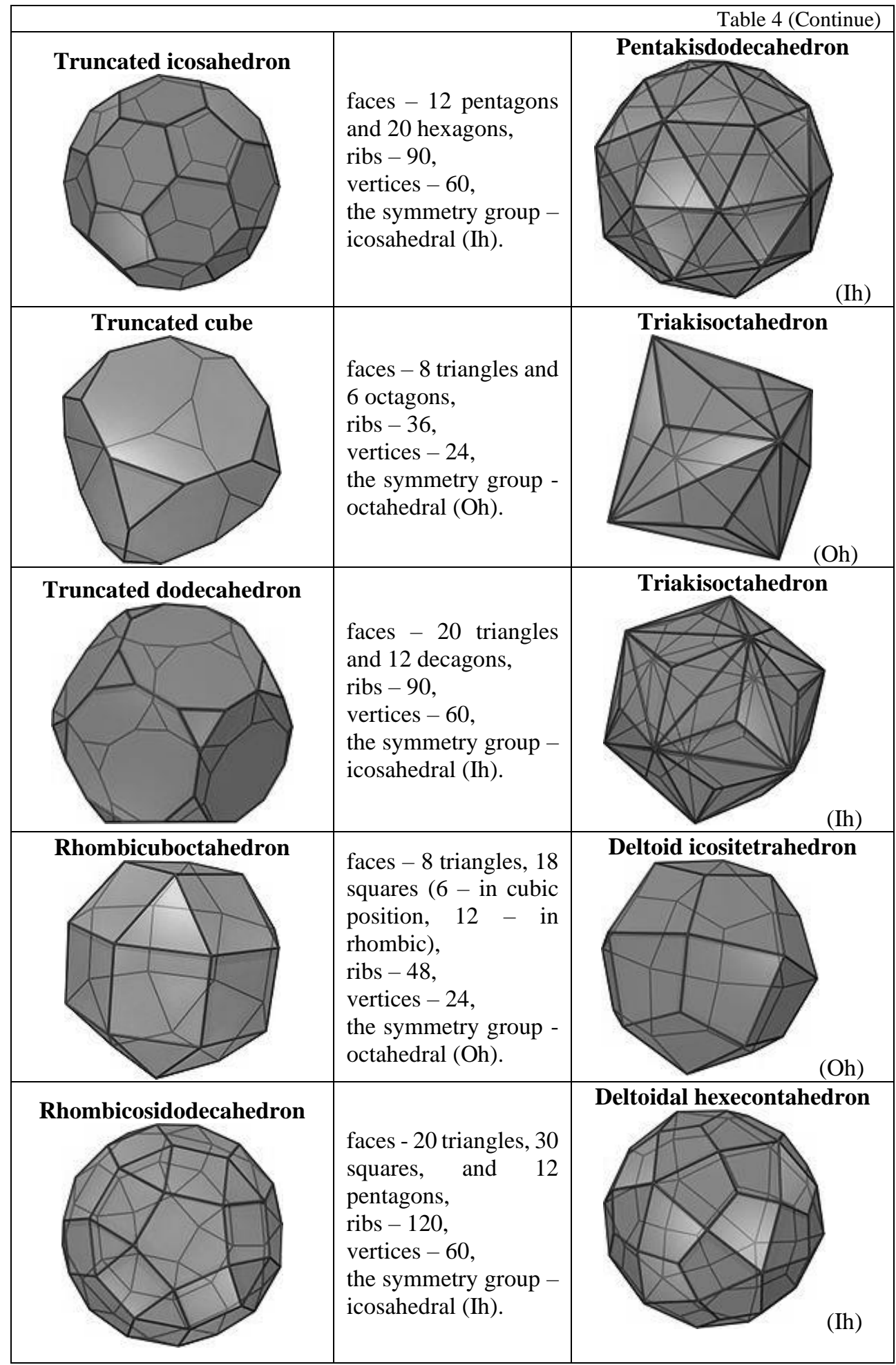




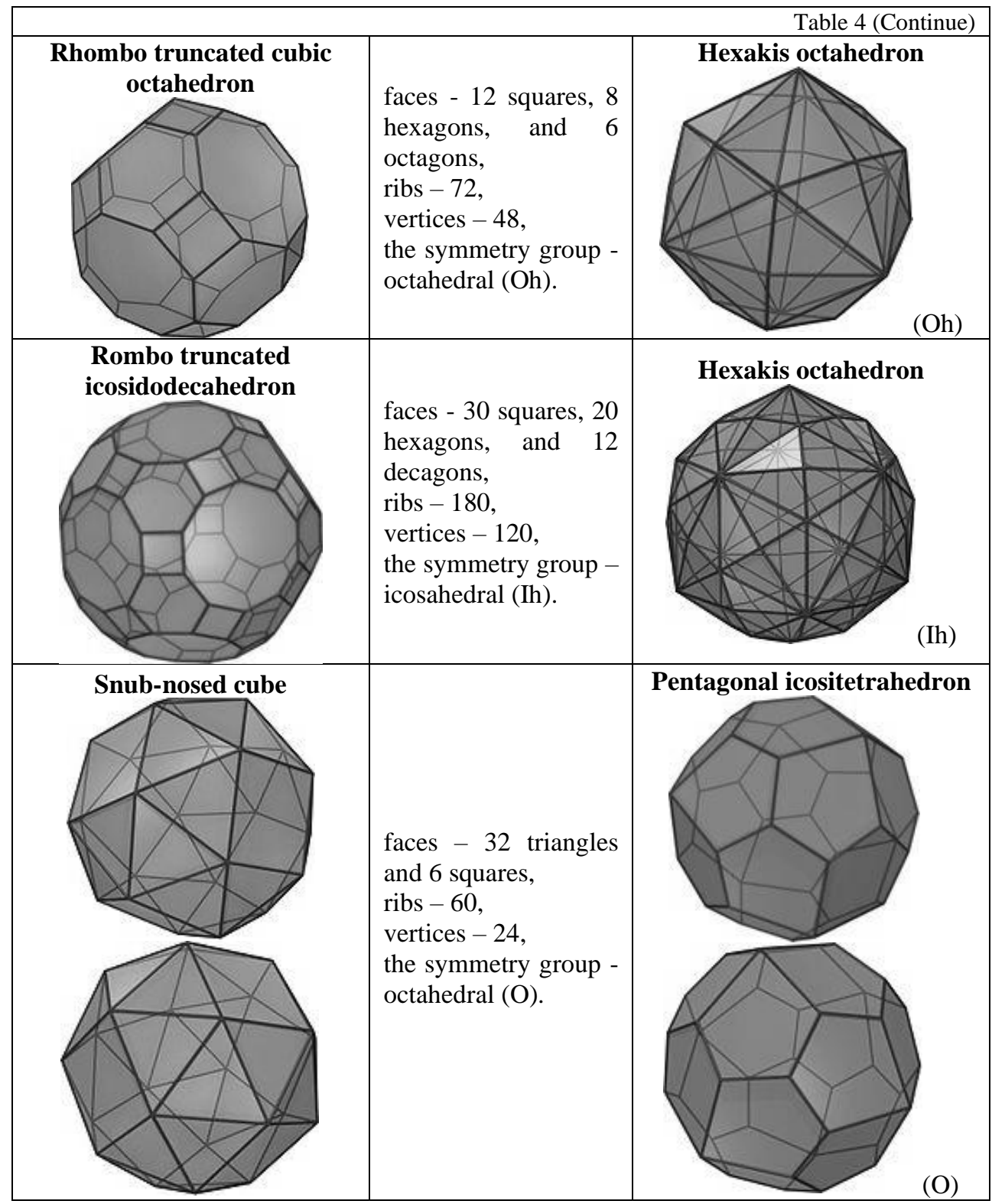




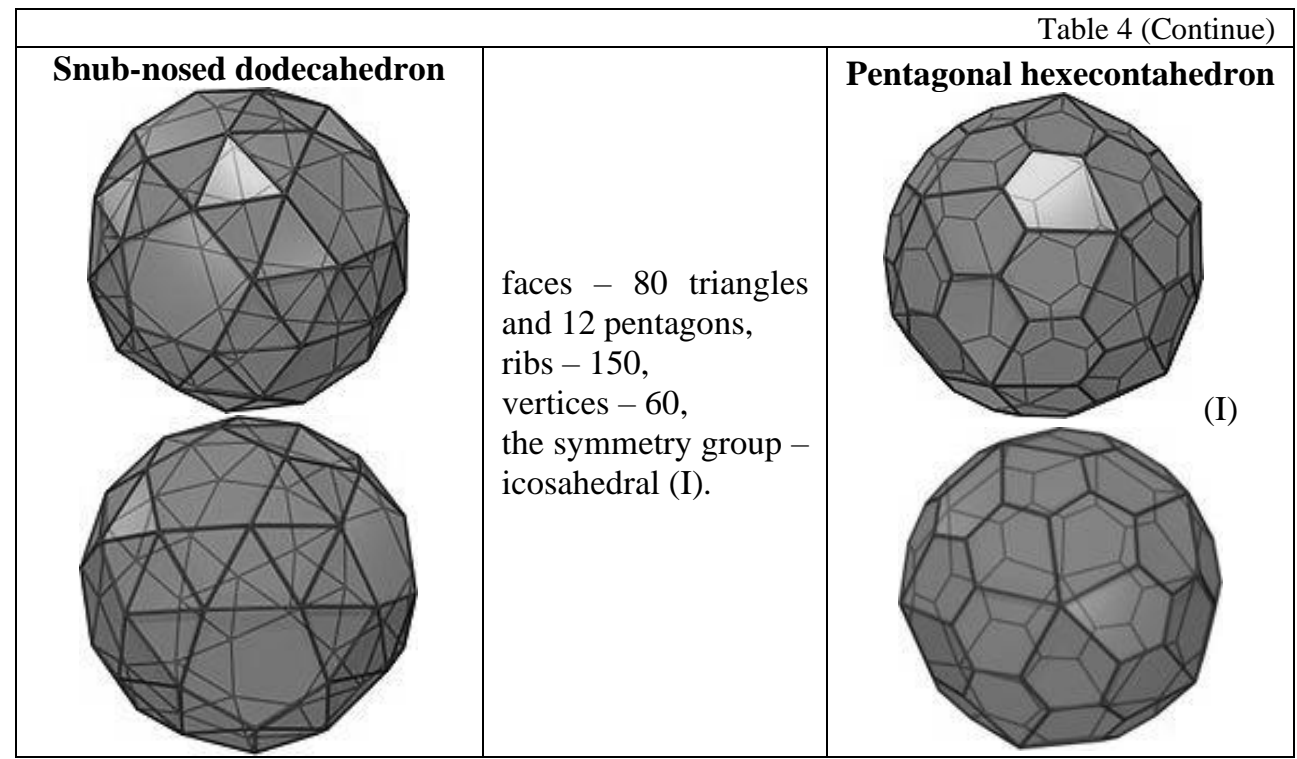

Crystals and their elementary cells can be described by axes of symmetry, which in some cases can be located at right angles to one another, in others at angles of $120^{\circ}$ (in the case of hexagonal and trigonal systems), or at other angles. Different systems are characterized by the following types of axes [33]:

- cubic system: three equal mutually perpendicular axes of length a;

- tetragonal system: two equal axes of length a and third axis of length c; all axes are mutually perpendicular;

- hexagonal or trigonal system: two equal axes of length a form an angle of $120^{\circ}$, the third axis of length $\mathrm{c}$ is at right angles to the first two;

- rhombic system: three axes of length, respectively, a, b, c, arranged perpendicular to each other;

- monoclinic system: two axes (a and c) form an angle $\beta$, and the third axis b is at right angles to the axes a and c;

- triclinic system: three axes a, b and c form angles $\alpha, \beta$ and $\gamma$.

There must be rational relations between the crystal faces and the axes: the segments of the axes cut off by the face refer to the lengths of the axes a, b and $c$ as Prime numbers.

By types of bonds all crystals can be divided into 5 groups [33]: ionic, covalent, metal, molecular and crystals with hydrogen bonds.

Thus, it can be assumed that the formation of taste sensations of great importance belongs to the geometry of the analyzed object. Apparently, the geometry of the taste receptors of the tongue and the analyzed taste objects is created on the principle of complementarity (i.e., by the type of lock-key) (Figure 8).

It is important to note that the analyzed objects of taste have not only a unique geometry and different sizes. Probably, taste analyzers are universal in relation to the size of the analyzed object and have a fractal structure that allows you to accurately determine the taste of any test sample [34]. 

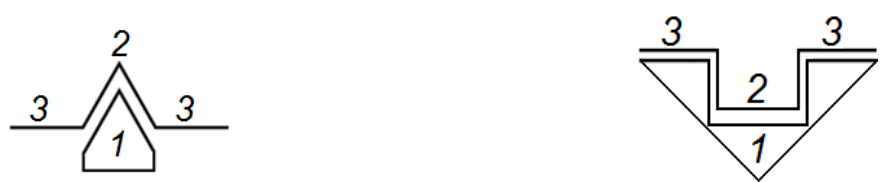

Figure 8. Possible geometry options on the principle of complementarity of the taste buds of the tongue and objects of taste:

1 - the object of taste; 2 - the taste receptor of the tongue; 3 - the surface of the tongue.

Fractal (lat. fractus - crushed, broken, broken) - a mathematical set that has the property of self-similarity, that is, uniformity in different scales of measurement. In mathematics, fractals are understood as sets of points in Euclidean space that have a fractional metric dimension (in the sense of Minkowski or Hausdorff), or a metric dimension different from the topological, so they should be distinguished from other geometric Figures limited by a finite number of links [34]. The most well-known at present and simple fractals (Koch curve, Levy curve and Hilbert curve) are presented in Figure 9.

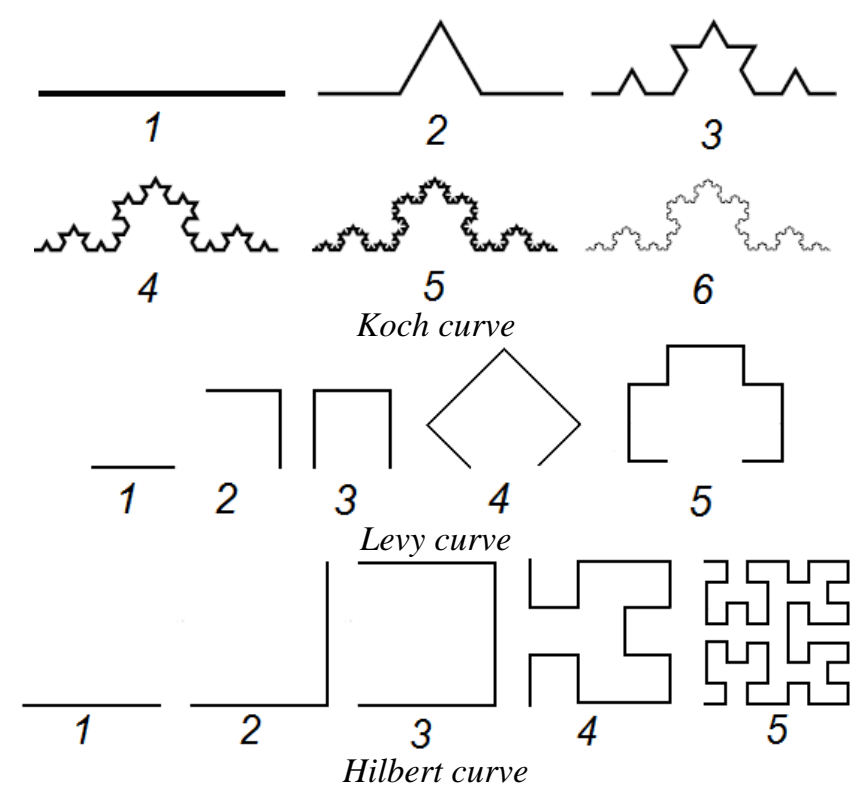

Figure 9. Known fractals:

1-6 - step-by-step construction of fractal curves

The fractal structure of the taste analyzers seems to be continuous. The surface geometry of the analyzed taste object has a complementary discontinuous fractal structure. The discontinuity of the fractal in the analyzed object of taste is probably due to the presence of various impurities. In nature, there are no completely pure substances. Due to the presence of a unique fractal discontinuity in various analyzed objects of taste there is a possibility of existence of such a large (infinite) variety of flavors. 
The smallest indivisible unit of a fractal, as the taste buds, and analyzed the object of taste is an electron. It is this elementary particle (electron) that determines the General geometry of fractals of taste analyzers and the analyzed object of taste. In addition, the number of electrons at the last energy level in atoms determines the complementarity of taste analyzers and the analyzed object of taste.

Currently, it is not known what an electron is and what geometry it has. So, once S. Berkovich admitted to L. Landau that no matter how «hollows» quantum mechanics, and the very essence of it can not grasp [35].

If our assumption is correct, taste receptors and analyzed taste objects have a fractalcomplementary structure, any type of taste and any flavor shade can be expressed by a mathematical formula.

It is now established that G-proteins are of great importance in the taste receptors of the tongue responsible for the perception of sweet and bitter taste [36]. So, G-proteins (persistent. $\mathrm{G}$ proteins) are a family of proteins related to GTPases that function as secondary mediators in intracellular signal cascades [37]. G-proteins are so named because in their signaling mechanism they use the replacement of GDP by GTP as a molecular functional «switch» to regulate cellular processes. G-proteins were discovered and studied by Alfred Gilman and Martin Rodbell, who received the 1994 Nobel prize in physiology or medicine for this discovery [38, 39]. G-proteins are divided into two main groups - heterotrimeric («large») and «small». Heterotrimeric G-proteins are proteins with Quaternary structure consisting of three subunits: alpha $(\alpha)$, beta $(\beta)$ and gamma $(\gamma)$. Small G-proteins are proteins from one polypeptide chain, they have a molecular mass of $20-25 \mathrm{kDa}$ and belong to the superfamily of Ras small GTPase. Their single polypeptide chain is homologous to the $\alpha$-subunit of heterotrimeric G-proteins. Both groups of G-proteins participate in intracellular signaling [37].

In the work of many G-proteins involved auxiliary proteins. GAPs (GTPase Activating Proteins, proteins-activators GTPase activity) accelerate the hydrolysis of GTP by accelerating the inactivation of G-proteins [37]. The function of GAPs is especially important for small G-proteins, because alpha subunits of heterotrimeric G-proteins often have sufficient GTPase activity themselves. Gap proteins are proteins of the RGS family.

GEFs (Guanine nucleotide Exchange Factors, guanyl nucleotide exchange factors), accelerate the exchange of GDF to GTP and thus activate G-proteins [37]. Typically, gprotein GEF-Ohm is activated by a ligand receptor, but in some cases, AGS proteins (Activator of G-protein signaling, g-protein signal transfer activators) can activate G-protein regardless of the effects of the receptor on it.

\section{Studies of milk proteins}

Many substances have a complex hierarchical structure and are able to «reveal» their taste characteristics stepwise, i.e. at each of the hierarchical levels of the organization of these substances have their taste characteristics. At the same time, it often happens that at the last hierarchical level the geometry of these substances tends to a spherical (neutral) form. To substances with complex and multilevel geometry can be attributed protein molecules (Figure 10 and 11). 


\section{Food Technology}

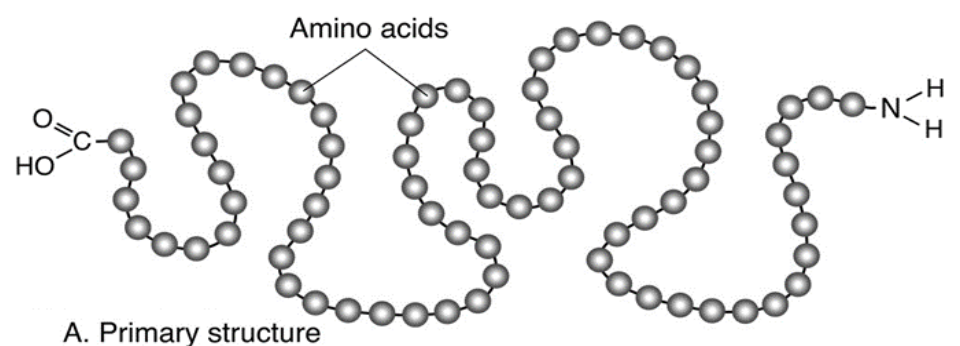

A. Primary structure
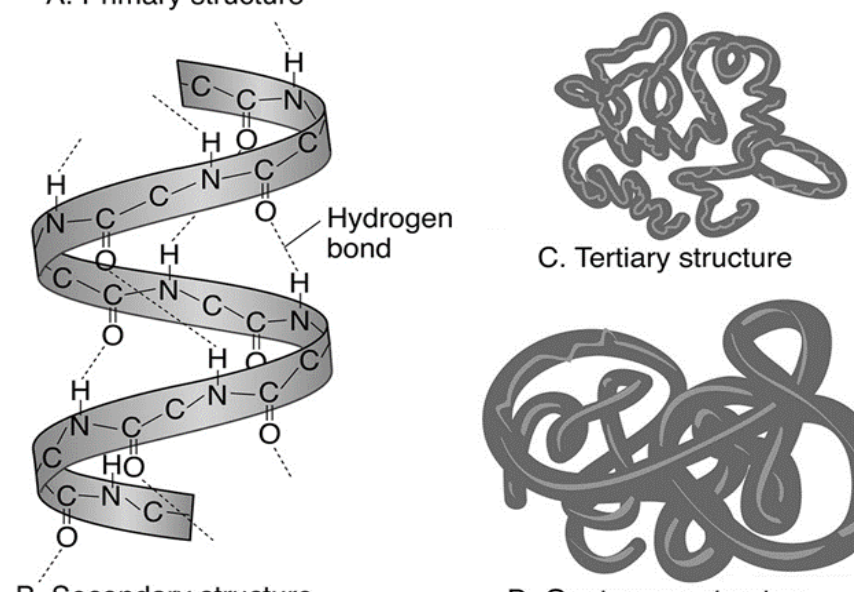

C. Tertiary structure

B. Secondary structure

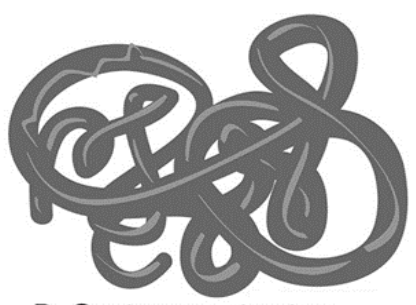

D. Quaternary structure

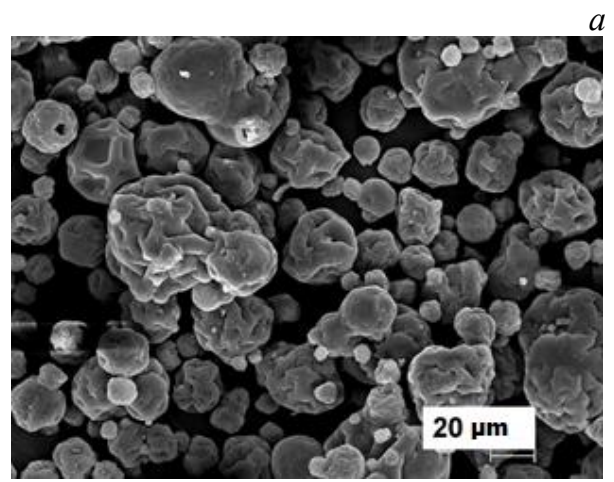

b

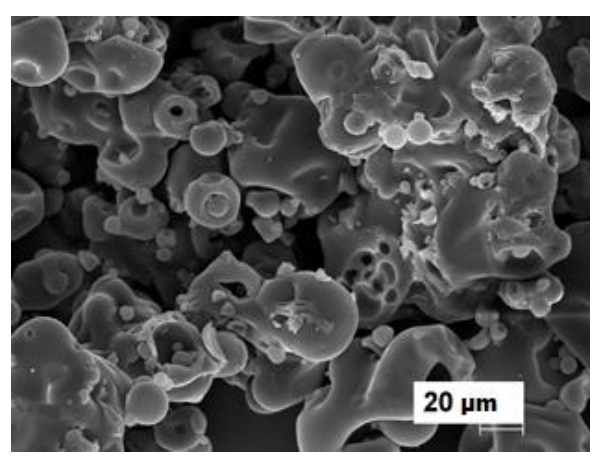

$c$

Figure 10. Features of the structure of protein molecules: a-levels of protein molecule structure;

Scanning electronic microphotographs of protein molecules: b-microparticulated whey protein concentrate Promilk 630M; c - whey protein concentrate KSB-UV-10 (JSC «Shchuchinsky MSZ»). 

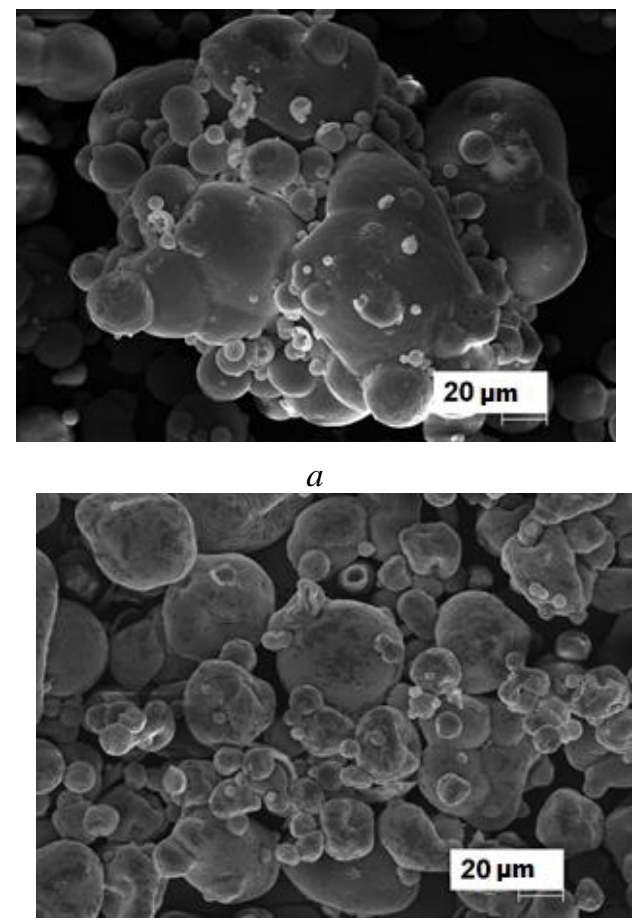

$c$

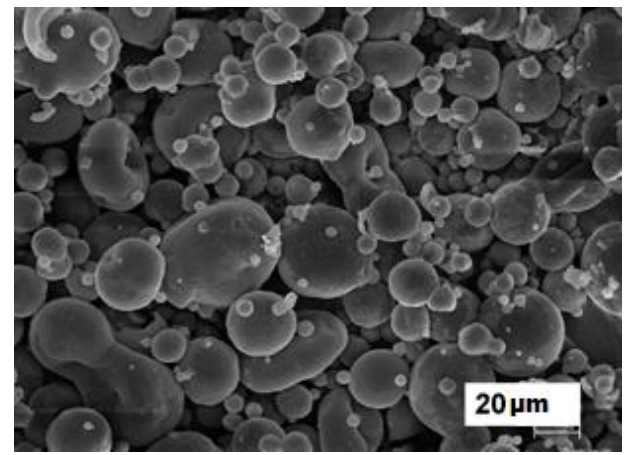

$b$

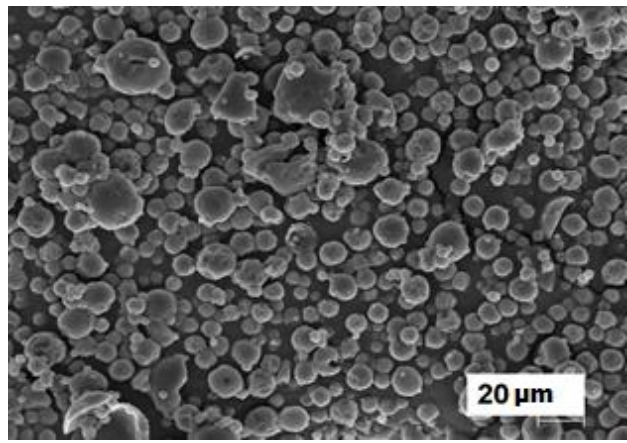

$d$

Figure 11. Scanning electron micrographs of protein molecules:

$a$ - whole milk for baby food with a fat content of $25 \%$ (JSC «Bellact»); $b$ - whey protein Simplesse 100E; $c$-skimmed milk powder (JSC «Bellakt»); $d$ - whey demineralized 50\%

Thus, protein molecules have primary, secondary, tertiary and quaternary structures [38, 39]:

1. The primary structure is the sequence of amino acid residues in the polypeptide chain of a protein molecule.

2. The secondary structure spatial configuration of the polypeptide chain:

- the $\alpha$-helix, stabilized by hydrogen bonds, has a step of $5,44 \AA$, a diameter of 10,5 $\AA$, for each coil of the spiral accounts for 3,7 amino acid residue;

- $\beta$-folded structure is a system of parallel or antiparallel segments of one or more polypeptide chains connected by hydrogen bonds; the basic identity period along the chain axis is $7,0 \AA$ in the case of parallel chains and $6,5 \AA$ in the case of antiparallel chains, and the distance between the chains is $9,5 \AA$.

3. Tertiary structure is the configuration of a polypeptide helix in space.

4. Quaternary structure - a set of polypeptide particles (subunits) representing a single molecular formation in structural and functional respect.

Proteins are conventionally divided depending on the shape of the molecule into two large groups: globular and fibrillar [38, 39]. Molecules of globular proteins are spherical or spindle-shaped; these proteins are soluble in water and aqueous solutions of salts. Fibrous proteins have elongated filamentous molecule and insoluble. In mammals, fibrillar proteins form the basis of supporting and covering tissues. 
By chemical composition proteins are classified into simple proteins (proteins) and complex proteins (proteids) [40, 41]. Simple proteins contain only $\alpha$-amino acids. The composition of complex proteins, in addition to amino acids, includes a non-protein part, the so-called prosthetic group. 41]:

Simple proteins, for lack of other criteria, are divided into seven solubility groups [40,

1. Albumins. Albumins are soluble in water, precipitate when the solution is saturated with ammonium sulfate, easily subjected to thermal denaturation. These proteins are found in both animals and plants, such as egg albumin, blood plasma albumin, milk lactalbumin, plant albumins.

2. Globulins. Globulins are insoluble in water, but dissolve in dilute salt solutions, precipitate when the solution is saturated with ammonium sulfate, coagulate when heated. To this group of simple proteins include the globulins of blood plasma, myosin of muscle tissue, edestin from seed.

3. Glutelins. Glutelin - plant proteins, insoluble in water, but soluble in dilute solutions of acids and alkalis, e.g. wheat glutenin and oryzenin from rice.

4. Prolamins. Prolamins - vegeTable proteins insoluble in water, salt solutions and absolute alcohol, but turning into a solution when treated with $80 \%$ aqueous alcohol. Basically these are proteins found in the seeds of plants (Zane, hordein, gliadin).

5. Albuminoids. Albuminoids (or scleroproteins) - simple proteins of animal origin, insoluble in water, salt solutions, alcohol and dilute acids and alkalis. Examples are proteins such as hair keratin, bone collagen, silk fibroin.

6. Protamines. The protamines - basic low molecular weight proteins with a high content of arginine. They are very soluble in water, insoluble in dilute ammonia solutions, do not coagulate when heated. Are composed of the sperm of fish, such as caprenin of sperm of common carp.

7. Histones. Histones dissolve in water and are insoluble in dilute ammonia; like protamines, do not denature when heated. Histones are also the main proteins, so in the cell they occur in the form of salt-like complexes with acidic components of it, most often with nucleic acids.

Complex proteins are classified depending on the nature non-protein component [40, 41]:

1. Nucleoproteins. Nucleoproteins consist of simple basic proteins (protamins or histones), which are connected by salt-like bonds with a non-protein component nucleic acids. They are typical substances of cell nuclei and ribosomes.

2. Glycoproteins. Glycoproteins are complex proteins that contain carbohydrates, such as connective tissue proteins, blood group substances, and certain hormones (gonadotropin).

3. Chromoproteins. Chromoproteins are complex proteins consisting of a simple protein and a colored prosthetic group. Examples of chromoproteins include hemoglobin, cytochromes, catalase, containing metalloporphyrin as a chromophore, as well as rhodopsin (visual purple), whose chromophore group is 11-CIS-retinal isomer, and flavoproteins with a prosthetic group - Riboflavin.

4. Phosphoproteins. The composition of phosphoproteins includes phosphoric acid, and it is shown that it forms an ether with a hydroxyl group of serine. Typical phosphoproteins are casein of milk and vitellin eggs.

5. Lipoproteins. Lipoproteins are complex proteins containing lipids (in particular, phospholipids), widely distributed in animals and plants. Lipoproteidnyi complexes are 


\section{— Food Technology —}

included in the protein of brain, blood, milk, chloroplasts of plants, etc. Lipoproteidna structure are also components of intracellular membranes.

\section{Discussion of the results}

Hierarchy in the structure of organic matter is maintained by means of hydrogen bonds and electrostatic interaction between the functional groups of matter and between different substances [42]. The hierarchical structure of substances can be disturbed by physical, chemical or combined factors, i.e. cooking [43, 44].

It follows from the above that if a material object has taste, it means that it is ordered in a certain way. Thus, the taste characteristics of a material object can be expressed with the

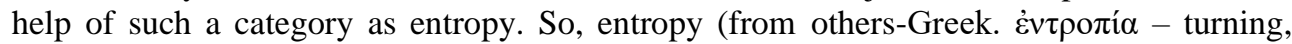
transformation) is a term widely used in the natural and exact Sciences [45]. The main value of entropy is a measure of disorderliness, randomness, disorder of the particles that make up the system [46, 47]. The category of entropy is related to information theory $[48,49]$.

It should be noted that both smell and taste are a form of chemoreception. Chemoreception - the ability of living things to perceive changes in the concentration of certain substances in the environment or in the body [50]. Therefore, we can assume that the features of the formation of sensations of smell will be similar to the formation of taste sensations.

\section{Conclusions}

As a result of our research it was found that:

1. In the formation of taste sensations of great importance belongs to the geometry of the taste buds of the language and the geometry of the analyzed objects of taste, which is created on the principle of complementarity (by type of lock-key). Taste analyzers of the tongue and analyzed objects of taste are universal in terms of size and have a fractal structure. The smallest indivisible fractal unit is the electron. The fractal structure of taste analyzers is continuous, and the analyzed taste objects are discontinuous and depend on the degree of purity of the object.

2. Among carbohydrates, glucose, fructose, sucrose, maltose, lactose and rhamnose have a crystalline structure, amorphous-crystalline (transitional or intermediate) structure native starches, and amorphous structure - maltodextrins.

3. Many substances (protein molecules, etc.) have a complex hierarchical structure and are able to show their taste characteristics stepwise, i.e. at each of the hierarchical levels of the organization of these substances have their taste characteristics. At the same time, it often happens that at the last hierarchical level the geometry of these substances tends to a spherical (neutral) form.

4. Smell as well as taste is one of the types of chemoreception, so the features of the formation of sensations of smell are similar to the formation of taste sensations.

\section{References}

1. Scinska A., Koros E., Habrat B., Kukwa A., Kostowski W., Bienkowski pp. (2000), Bitter and sweet components of ethanol taste in humans, Drug and Alcohol Dependence, 60(2), pp. 199-206. 
2. Wang X. (2004), Relaxation of Selective Constraint And Loss of Function In The Evolution of Human Bitter Taste Receptor Genes, Human Molecular Genetics, 13(21), pp. 2671-2678.

3. Maehashi K., Matano M., Wang H., Vo L.A., Yamamoto Y., Huang L. (2008), Bitter peptides activate hTAS2Rs, the human bitter receptors, Biochem. Biophys. Res. Commun, 365(4), pp. 851-855.

4. Meyerhof A. (2010), The molecular receptive ranges of human TAS2R bitter taste receptors, Chem. Senses, 35(2), pp. 157-170.

5. Wiener S. (2012), BitterDB: a database of bitter compounds, Nucleic Acids Res, 40 D4139.

6. Wang, X., Thomas S.D., Zhang J. (2004), Relaxation of selective constraint and loss of function in the evolution of human bitter taste receptor genes, Hum. Mol. Genet, 13(21), pp. 2671-2678.

7. Wooding, S., Kim U.K., Bamshad M.J., Larsen J., Jorde L.B., Drayna D. (2004), Natural selection and molecular evolution in PTC, a bitter-taste receptor gene, Am. J. Hum. Genet, 74(4), pp. 637-646.

8. Chang R., Waters H., Liman E. (2010), A proton current drives action potentials in genetically identified sour taste cells, Proc. Natl. Acad Sci. USA, 107(51), pp. 2232022325.

9. Ye W., Chang R.B., Bushman J.D., Tu Y.H., Mulhall E.M., Wilson C.E., Cooper A.J., Chick W.S., Hill-Eubanks D.C., Nelson M.T., Kinnamon S.C. Liman E.R. (2016), The $\mathrm{K}^{+}$channel KIR2.1 functions in tandem with proton influx to mediate sour taste transduction, Proc. Natl. Acad. Sci. USA, 113(2), pp. E229-238.

10. Liem D.G., Mennella J.A. (2003), Heightened Sour Preferences During Childhood, Chem. Senses, 28(2). pp. 173-180.

11. Tu Y.H. (2018), An evolutionarily conserved gene family encodes proton-selective ion channels, Science, 359, pp. 1047-1050.

12. Lindemann B. (2010), A taste for umami, Nature Neuroscience, 3(2), pp. 99-100.

13. Nelson G., Chandrashekar J., Hoon M.A. et al. (2002), An amino-acid taste receptor, Nature, 416(6877), pp. 199-202.

14. Gayvoronsky I.V. (2001), Normal human anatomy, Sankt-Peterburg.

15. Prives M.G., Lysenko N.T., Bushkovich V.I. (1985), Human anatomy, Moscow.

16. Polishchuk V.R. (1979), How to make out a molecule, Chemistry, Moscow.

17. Khabas T.A., Vakalova T.V., Gromov A.A., Kulinich E.A. (2007), X-ray phase analysis, Tomsk.

18. McMullan D. (1988), Von Ardenne and the scanning electron microscope, Proc Roy Microsc Soc, 23, pp. 283-288.

19. Mignot, Christophe (2018), Color (and 3D) for Scanning Electron Microscopy, Microscopy Today, 26(3), pp. 12-17.

20. Makhiyanova E.B. (2019), Big Atlas of Human Anatomy, Moscow.

21. Bilich G.L., Zigalova E.Yu. (2018), Atlas: Anatomy and Human Physiology. The full practical manual, Moscow.

22. Kim A.M. (2004), Organic chemistry: textbook, Novosibirsk.

23. Acosta V., Kovan K., Graham B. (1981), Fundamentals of modern physics, Education, Moscow.

24. Production/processing. Sugar industry. About sugar. Properties of sucrose, Available at: http://optinfo.ru/author/?id=592.

25. Tuzhilkin V.I. (2007), Sugar crystallization. Moscow. 
26. Lovkis Z.V., Litvyak V.V., Petyushev N.N. (2007), Technology of starch and starch products, Asobny, Minsk.

27. Zhukov A.V. (2007), The ubiquitous pi, Publishing House LCI, Moscow.

28. David H. Bailey, Jonathan M. Borwein (2016), Pi: The Next Generation A Sourcebook on the Recent History of Pi and Its Computation, Springer.

29. Nekrasov B.V. (1973), Fundamentals of General chemistry. In 2 volumes. Chemistry, Moscow.

30. Glinka M.L. (1982), General chemistry (textbook), Kyiv.

31. Gonchar V.V., Gonchar D.R. (2010), Polyhedron models, Phoenix, Rostov-on-Don.

32. Ashkinuse V.G. (1957), On the number of semi-regular polyhedral, Mathematical education, 1, pp. 107-118.

33. Weinstein B.K. (1981), Modern crystallography. In 4 volumes, Science, Moscow.

34. Mandelbrot B. (2001), Fractal geometry of nature, Book house, Minsk.

35. Reznik S. (1993), How the world works (the hypothesis of professor S. Berkovich). Chemistry and life, 9, pp. 14-21.

36. Bronstein A.I. (1956), Taste and sense of smell, Leningrad.

37. Neves S.R., Ram pp.T., Iyengar R. (2002), G Protein Pathways, Science, 296, pp. 16361639.

38. The Nobel Prize in Physiology or Medicine 1994: Alfred G. Gilman - Biographic, Available at: http://www.nobelprize.org/nobel_prizes/medicine/laureates/1994/gilmanbio.html

39. The Nobel Prize in Physiology or Medicine 1994: Martin Rodbell - Biographic, Available at: http://www.nobelprize.org/nobel_prizes/medicine/laureates/1994/rodbellbio.html.

40. Leninger A. (1985), Fundamentals of Biochemistry. In 3 volumes, Moscow

41. Lovkis Z.V., Pochitskaya I.M., Melsitova I.V., Litvyak V.V. (2010), Food quality and safety, IVTSminfina, Minsk.

42. Epstein L.M., Shubina E.S. (2003), The Many-Faced Hydrogen Bond, Nature, 6, pp. 4045.

43. Pokhlebkin V.V. (2003), Entertaining Cooking, Centerpolygraph, Moscow

44. Pokhlebkin V.V. (1988), On Cooking from A to Z: Dictionary Dictionary, Polymya, Minsk.

45. Prigozhin I., Stengers I. (1986), Order out of chaos. A new dialogue between man and nature, Progress, Moscow.

46. Csiszár I. (2008), Axiomatic Characterizations of Information Measures, Entropy, 10, pp. 261-273.

47. Cichocki A., Amari S.-I. (2010), Families of Alpha- Beta- and Gamma divergences: Flexible and robust measures of similarities, Entropy, 12, pp. 1532-1568.

48. Tsypkin Y.Z. (1995), Information Theory of Identification, Science, Moscow

49. Zaripov R.G. (2005), New measures and methods in information theory, Kazan.

50. Sinitsina E.E., Chaika S.Yu. (2006), Atlas of electron microscopic morphology of the chemoreceptor organs of insects, Moscow. 